\title{
Correction to: Economic evaluation of the life cycle of a wind farm and improving the levelized cost of energy in region Champagne-Ardenne, France
}

\author{
Abdelouahab Zaoui ${ }^{1,4} \cdot$ Rachid Meziane ${ }^{1,4} \cdot$ Eric Chatelet $^{2} \cdot$ Fatiha Lakdja $^{3,4} \cdot$ Nacef Tazi $^{2} \cdot$ Youcef Bouzidi $^{2}$
}

Published online: 27 December 2021

( ) The Author(s), under exclusive licence to Islamic Azad University 2021

\section{Correction to: \\ International Journal of Energy and Environmental Engineering \\ https://doi.org/10.1007/s40095-021-00425-w}

Unfortunately, the two co-authors, Nacef Tazi and Youcef Bouzidi, were not included in the original article.

The correct authorship is as follows:

Abdelouahab Zaoui ${ }^{1,4} \cdot$ Rachid Meziane ${ }^{1,4} \cdot$ Eric Chatelet $^{2}$ - Fatiha Lakdja ${ }^{3,4}$. Nacef Tazi ${ }^{2}$. Youcef Bouzidi ${ }^{2}$

${ }^{1}$ Electro-Technical Engineering Laboratory, Faculty of Technology, University of Saida, Saïda, Algeria

${ }^{2}$ Charles Delaunay Institute, LM2S/STMR, CNRS, University of Technology of Troyes, Troyes, France
${ }^{3}$ Intelligent Control and Electric Power System Laboratory (ICEPS), Djillali Liabes University of Sidi-Bel-Abbes, Sidi Bel Abbes, Algeria

${ }^{4}$ Department of Electrical Engineering, University of Saida, Saïda, Algeria

Publisher's Note Springer Nature remains neutral with regard to jurisdictional claims in published maps and institutional affiliations.

The original article can be found online at https://doi.org/10.1007/ s40095-021-00425-w.

Abdelouahab Zaoui

abdelouahab.zaoui@univ-saida.dz

1 Electro-Technical Engineering Laboratory, Faculty of Technology, University of Saida, Saïda, Algeria

2 Charles Delaunay Institute, LM2S/STMR, CNRS, University of Technology of Troyes, Troyes, France

3 Intelligent Control and Electric Power System Laboratory (ICEPS), Djillali Liabes University of Sidi-Bel-Abbes, Sidi Bel Abbes, Algeria

4 Department of Electrical Engineering, University of Saida, Saïda, Algeria 